\title{
Interstage evaluation of homograft-valved right ventricle to pulmonary artery conduits for palliation of hypoplastic left heart syndrome
}

\author{
Nefthi Sandeep, MD, ${ }^{\mathrm{a}}$ Rajesh Punn, MD, ${ }^{\mathrm{b}}$ Sowmya Balasubramanian, MD, ${ }^{\mathrm{b}}$ Shea N. Smith, MD, \\ Olaf Reinhartz, MD, ${ }^{a}$ Yulin Zhang, PhD, ${ }^{a}$ Gail E. Wright, MD, ${ }^{b}$ Lynn F. Peng, MD, ${ }^{b}$ \\ Lisa Wise-Faberowski, MD, ${ }^{c}$ Frank L. Hanley, MD, ${ }^{a}$ and Doff B. McElhinney, MD ${ }^{a, b}$
}

\section{ABSTRACT}

Objective: Palliation of hypoplastic left heart syndrome with a standard nonvalved right ventricle to pulmonary artery conduit results in an inefficient circulation in part due to diastolic regurgitation. A composite right ventricle pulmonary artery conduit with a homograft valve has a hypothetical advantage of reducing regurgitation, but may differ in the propensity for stenosis because of valve remodeling.

Methods: This retrospective cohort study included 130 patients with hypoplastic left heart syndrome who underwent a modified stage 1 procedure with a right ventricle to pulmonary artery conduit from 2002 to 2015. A composite valved conduit (cryopreserved homograft valve anastomosed to a polytetrafluoroethylene tube) was placed in 100 patients ( 47 aortic, 32 pulmonary, 13 femoral/saphenous vein, 8 unknown), and a nonvalved conduit was used in 30 patients. Echocardiographic functional parameters were evaluated before and after stage 1 palliation and before the bidirectional Glenn procedure, and interstage interventions were assessed.

Results: On competing risk analysis, survival over time was better in the valved conduit group $(P=.040)$, but this difference was no longer significant after adjustment for surgical era. There was no significant difference between groups in the cumulative incidence of bidirectional Glenn completion $(P=.15)$. Patients with a valved conduit underwent more interventions for conduit obstruction in the interstage period, but this difference did not reach significance $(P=.16)$. There were no differences between groups in echocardiographic parameters of right ventricle function at baseline or pre-Glenn.

Conclusions: In this cohort of patients with hypoplastic left heart syndrome, inclusion of a valved right ventricle to pulmonary artery conduit was not associated with any difference in survival on adjusted analysis and did not confer an identifiable benefit on right ventricle function. (J Thorac Cardiovasc Surg 2018;155:1747-55)

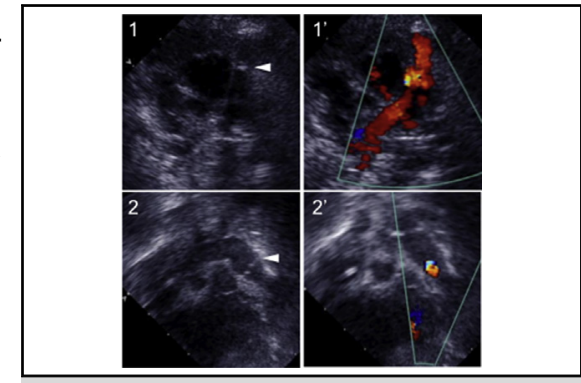

Two-dimensional and color Doppler images of homograft valved RV-PA conduits in 2 patients.

\section{Central Message}

Using a valved RV to PA conduit to palliate HLHS neither improved survival to BDG nor altered RV function.

\section{Perspective}

Placement of a valve in the RV to PA conduit in patients undergoing stage 1 palliation of HLHS did not provide a clear benefit in survival to BDG and was not associated with any difference in RV function in the interstage period compared with use a non-VC.

See Editorial Commentary page 1756.

See Editorial page 1745.
Hypoplastic left heart syndrome (HLHS) is the most common form of functionally single ventricle heart disease, with an estimated incidence of 2.3 cases per 10,000 live

\footnotetext{
From the Lucile Packard Children's Hospital Heart Center and Departments of a Cardiothoracic Surgery, ${ }^{b}$ Pediatrics, and ${ }^{\mathrm{c}}$ Anesthesia, Stanford University School of Medicine, Palo Alto, Calif.

Received for publication April 4, 2017; revisions received Oct 18, 2017; accepted for publication Nov 1, 2017; available ahead of print Dec 6, 2017

Address for reprints: Doff B. McElhinney, MD, Stanford University, 780 Welch Rd, Suite CJ110, Palo Alto, CA 94304 (E-mail: doff@stanford.edu). $0022-5223 / \$ 36.00$

Copyright (C) 2017 by The American Association for Thoracic Surgery https://doi.org/10.1016/j.jtcvs.2017.11.001
}

births. ${ }^{1}$ Despite surgical advances to palliate HLHS, systemic right ventricular (RV) failure remains a significant cause of morbidity, with an estimated prevalence of $11 \%$ at 3 months after stage 1 palliation. ${ }^{2}$ Initial palliative surgery for HLHS uses a conduit from the systemic RV to the pulmonary artery (PA) or a modified Blalock-Taussig

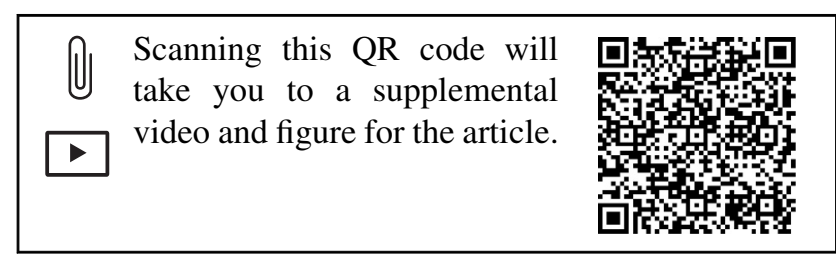




$$
\begin{aligned}
& \text { Abbreviations and Acronyms } \\
& \mathrm{BDG}=\text { bidirectional Glenn } \\
& \text { ECMO }=\text { extracorporeal membrane oxygenation } \\
& \text { FAC }=\text { fractional area change } \\
& \text { HLHS = hypoplastic left heart syndrome } \\
& \text { HR = hazard ratio } \\
& \text { mBTS }=\text { modified Blalock-Taussig shunt } \\
& \mathrm{NVC}=\text { nonvalved conduit } \\
& \mathrm{PA}=\text { pulmonary artery } \\
& \text { PTFE = polytetrafluoroethylene } \\
& \mathrm{RV} \quad=\text { right ventricle } \\
& \text { TAPSE }=\text { tricuspid valve annular plane systolic } \\
& \text { excursion } \\
& \mathrm{TR}=\text { tricuspid regurgitation } \\
& \mathrm{TV}=\text { tricuspid valve } \\
& \mathrm{VC}=\text { valved conduit }
\end{aligned}
$$

use of a valved conduit (VC) or nonvalved conduit (NVC) RV-PA conduit.

\section{MATERIALS AND METHODS \\ Study Population and Design}

We performed a retrospective analysis of all patients with HLHS and HLHS variants who underwent a stage 1 procedure with an RV-PA conduit (Sano modification) at Lucile Packard Children's Hospital Stanford from January 2002 to August 2015. All patients received follow-up care at our institution and were followed until one of the following end points occurred: completion of a bidirectional Glenn (BDG) procedure (survival through 30 days post-BDG and hospital discharge), death, or transplant. All data were obtained from medical records or clinical databases. The study was approved by the Stanford University Research Compliance Office/Institutional Review Board.

\section{Operative Technique}

Details regarding operative technique and conduit size selection were described previously. ${ }^{11}$ In brief, a composite conduit was created by sewing the distal end of a polytetrafluoroethylene (PTFE) tube (usually $5 \mathrm{~mm}$, with or without ring reinforcement) to an aortic or pulmonary homograft valve (usually 1-2 mm larger than the PTFE tube) and then inserting the valved conduit (VC) between an RV infundibulotomy and the PA bifurcation to the left side of the neoaorta. In a minority of cases, a valved saphenous or femoral vein homograft was used instead and implanted in similar fashion. Regardless of conduit or valve type, patients were maintained on aspirin but no additional anticoagulation.

\section{Echocardiography}

Clinical echocardiograms just before the stage 1 palliation and stage 2 BDG palliation were reviewed independently by the study authors (NS, RP, and SNS) for the following functional parameters: RV 2-dimensional fractional area change (FAC) and tricuspid valve (TV) annular plane systolic excursion (TAPSE), and the presence of moderate or greater TR. TV annulus measurements were converted into $z$ scores and used as a 2-dimensional surrogate measure of RV size. ${ }^{12}$ RV FAC, TAPSE, and TV annulus diameters were all obtained from the apical- 4 chamber view. TR was evaluated in multiple imaging planes and graded as none, trace, mild, moderate, or severe by qualitative assessment of jet width. In patients who did not complete a BDG procedure but had an echocardiogram available for review at an age beyond the earliest BDG in the cohort, that echocardiogram was included in the analysis.

To assess homograft valve competence in the VC group, the first echocardiogram performed after the stage 1 procedure and the last echocardiogram performed before the BDG procedure were reviewed for the presence of a vena contracta jet of regurgitation in proximity to the valve within the RV-PA conduit (Figure 1). Vena contracta width was normalized to the valve diameter (at implant) and used as a surrogate measure of conduit valve competence; vena contracta widths were expressed both in absolute terms (millimeters) and as a percentage of the implanted valve diameter.

\section{Invasive Hemodynamics and Interventions}

Interstage hemodynamic data from cardiac catheterization before BDG were recorded. If the systemic oxygen saturation was not reported or recorded on the day of pre-BDG catheterization, it was obtained from the medical record within a few days of the procedure. For this study, we ascertained interventions on the pulmonary circulation after the stage 1 procedure and before BDG. We defined intervention as a percutaneous or surgical procedure performed after the initial stage 1 procedure to augment, reduce, or improve the distribution of pulmonary blood flow (excluding 

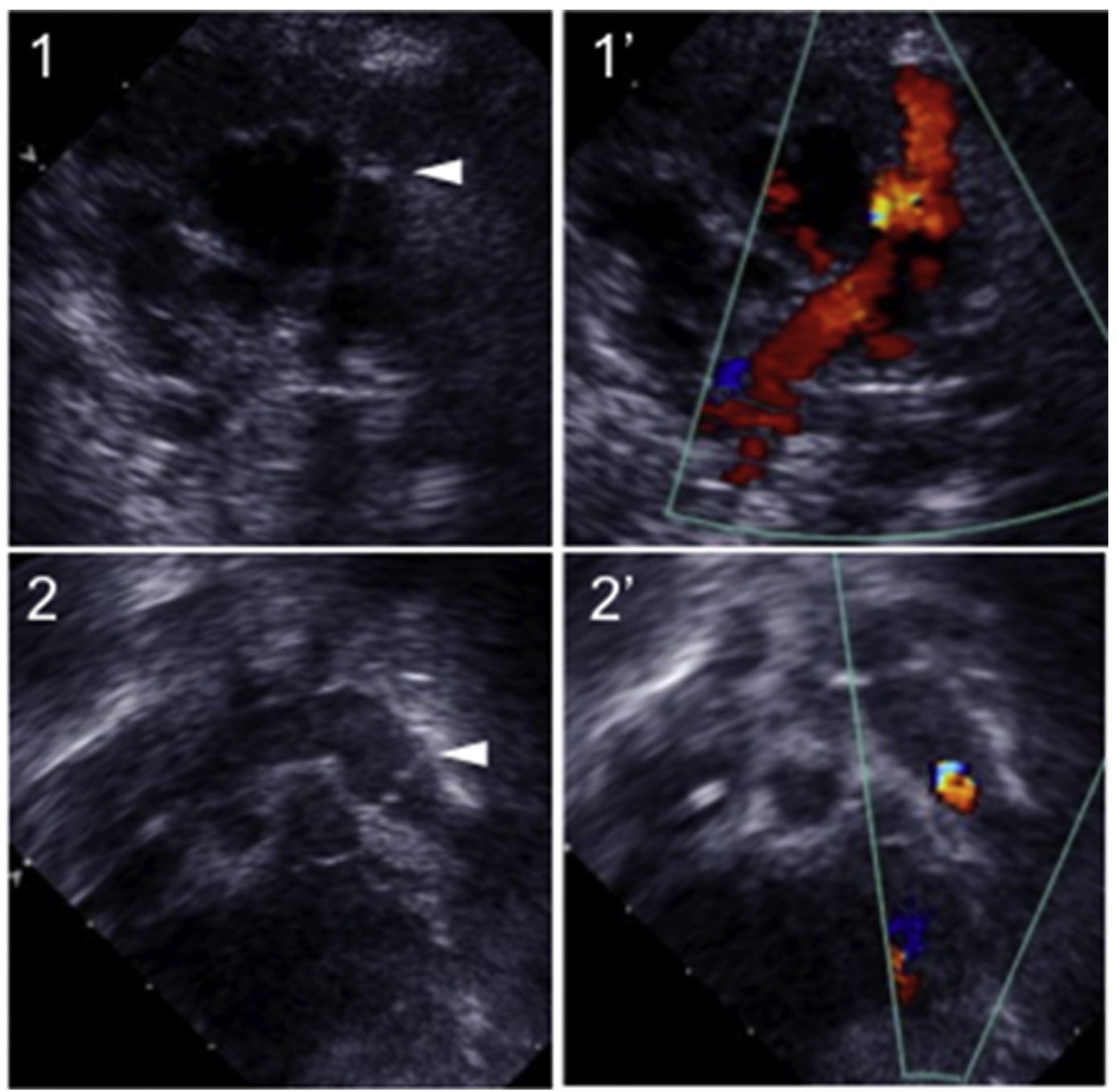

FIGURE 1. Two-dimensional and color Doppler images of homograft valved RV-PA conduits in 2 patients demonstrating the valve itself (arrowheads) as well as the vena contracta of the insufficiency jet. The vena contracta width was measured to assess valve competency.

closure of aortopulmonary or venous collaterals). Interventions were categorized as early if they were performed within 30 days of the stage 1 procedure and late if beyond 30 days.

\section{Statistical Analysis}

Continuous variables were compared between groups using independent samples $t$ test or Mann-Whitney $U$ test. Categoric data were compared between groups using the chi-square or Fisher exact test. The primary outcome was survival through BDG or to 1 year of age, whichever was earlier. Because of variability in timing of the BDG, midterm freedom from death or transplant was evaluated through 30 days after BDG completion or 1 year of age if BDG had not yet been performed. Specifically, patients were censored event-free 30 days after a successful BDG or at 1 year of age if a BDG had not been performed by that time. To account for competing outcomes (ie, death and BDG), we performed competing risk analysis to compare VC and NVC groups, using Gray's test of cumulative incidence. To adjust for potential confounding by other factors, stratified analysis was performed, incorporating variables that were also associated with the cumulative incidence outcome. Freedom from surgical or percutaneous intervention related to pulmonary blood flow, and freedom from intervention for conduit obstruction was analyzed using Kaplan-Meier curves and Cox regression analysis, with multivariable analysis if appropriate. Hazard ratios (HRs) were presented with $95 \%$ confidence intervals. Early outcomes (the longer of 30 days or hospital discharge) after the stage 1 procedure were also compared between groups using logistic regression, with adjustment for surgical era, surgeon, intact/restrictive atrial septum, prematurity, and mitral stenosis/aortic atresia subtype. Comparison of echocardiographic data between groups at prestage 1 and pre-BDG, and comparison of changes in these variables from prestage 1 to pre-BDG, was performed using the $t$ test or Fisher exact test. Comparison of echocardiographic variables from prestage 1 to pre-BDG, both overall and within conduit groups, was performed with paired $t$ test. Data were analyzed at a significance level of .05 and presented as mean \pm standard deviation or median (minimum-maximum). Data were analyzed using R version 3.3.1 and SPSS version 23 (IBM, Armonk, NY).

\section{RESULTS}

\section{Patient Demographics}

A total of 142 patients were identified with HLHS and HLHS variants who received an RV-PA conduit during the stage 1 procedure and received follow-up care at our 
institution. Eleven patients were excluded because the stage 1 procedure was performed at an outside institution or reliable operative data specifying the type of conduit used were not available. One patient was excluded because an mBTS was placed in addition to the RV-PA conduit at the stage 1 procedure. Thus, 130 patients were included in the analysis: A total of 100 patients received a VC and 30 patients received an NVC (Table 1). There was decreasing use of the VC during the latter half of this experience $(P<.001)$, and there were differences in the distribution of shunt type among the 3 surgeons who performed these procedures. ${ }^{13}$ Other high-risk characteristics, such as prematurity, the presence of an intact atrial septum, HLHS subtype, and moderate or severe TR, were similarly represented in both groups. Age and weight at stage 1 were similar in the VC and NVC groups, and RV-PA conduit size did not differ.

\section{Bidirectional Glenn Completion}

Successful BDG was achieved in 77 patients with a VC at a median age of 120 days (77-376) and 17 patients with an

TABLE 1. Demographic, diagnostic, procedural, and outcome data

\begin{tabular}{|c|c|c|c|}
\hline & $\begin{array}{c}\text { VC } \\
(n=100)\end{array}$ & $\begin{array}{c}\text { NVC } \\
(\mathbf{n}=\mathbf{3 0})\end{array}$ & $\begin{array}{c}P \\
\text { value }\end{array}$ \\
\hline Era 1 (first half of experience) & $61(61 \%)$ & $4(13 \%)$ & $<.001$ \\
\hline Gestational age at birth (wk) & $39(31.4-41.6)$ & $39(36-40.7)$ & .91 \\
\hline Gestational age $<37$ wk & $13(13 \%)$ & $2(7) \%$ & .34 \\
\hline Age at stage $1(\mathrm{~d})$ & $5(1-37)$ & $5(1-11)$ & .57 \\
\hline Weight at stage $1(\mathrm{~kg})$ & $3.2 \pm 0.5$ & $3.2 \pm 0.5$ & 1.0 \\
\hline Weight $<2.5 \mathrm{~kg}$ & $11(11 \%)$ & $2(7 \%)$ & .41 \\
\hline Male sex & $62(62 \%)$ & $15(50 \%)$ & .29 \\
\hline Intact atrial septum & $8(8 \%)$ & $0(0 \%)$ & .20 \\
\hline $\begin{array}{l}\text { Mitral stenosis/aortic atresia } \\
\text { subtype }\end{array}$ & $22(22 \%)$ & $7(23 \%)$ & 1.0 \\
\hline $\begin{array}{l}\text { RV-PA conduit diameter* } \\
\qquad \begin{array}{l}* \mathrm{~mm} \\
5 \mathrm{~mm} \\
6 \mathrm{~mm}\end{array}\end{array}$ & $\begin{array}{c}5(5 \%) \\
77(79 \%) \\
16(16 \%)\end{array}$ & $\begin{array}{c}1(3 \%) \\
24(80 \%) \\
5(17 \%)\end{array}$ & .92 \\
\hline $\begin{array}{l}\text { RV-PA conduit valve type* } \\
\text { Aortic homograft } \\
\text { Pulmonary homograft } \\
\text { Femoral/saphenous vein } \\
\text { homograft }\end{array}$ & $\begin{array}{l}47(51 \%) \\
32(35 \%) \\
13(14 \%)\end{array}$ & $\begin{array}{l}- \\
- \\
-\end{array}$ & - \\
\hline $\begin{array}{l}\text { RV-PA conduit valve diameter } \dagger \\
5 \mathrm{~mm} \\
6 \mathrm{~mm} \\
7 \mathrm{~mm} \\
8 \mathrm{~mm}\end{array}$ & $\begin{array}{c}1(1 \%) \\
39(40 \%) \\
52(53 \%) \\
5(5 \%)\end{array}$ & $\begin{array}{l}- \\
- \\
- \\
-\end{array}$ & - \\
\hline
\end{tabular}

Data presented as median (minimum-maximum), mean \pm standard deviation, or number $(\%)$ where indicated. $P$ values are for $t$ test, Mann-Whitney, or chi-square/ Fisher exact test. $V C$, Valved conduit; $N V C$, nonvalved conduit; $R V-P A$, right ventricle-pulmonary artery. *Data available for $92 \mathrm{VC}$ patients. $\dagger$ Data available for $97 \mathrm{VC}$ cases.
NVC at a median age of 123 days (96-218), with no difference in the cumulative incidence of BDG completion $(P=.15)$ (Figure 2, A). In the VC group, 76 patients completed a BDG by the age of 276 days ( 4 of these were aged 6-12 months) and 1 patient at 376 days. In the NVC group, 17 patients had completed a BDG by age 218 days, including only 1 who underwent BDG between 6 and 12 months. The median age at BDG procedure was similar between groups.

\section{Mortality}

Early mortality after the stage 1 procedure (within 30 days or during the same hospitalization) was $18 \%$ overall and did not differ between the VC $(\mathrm{n}=15,15 \%)$ and NVC $(\mathrm{n}=8,27 \%)$ groups $(P=.14)$ on unadjusted analysis or after adjustment for other risk factors. Cardiopulmonary resuscitation with extracorporeal membrane oxygenation (ECMO) in the early poststage 1 period was performed in $10 \mathrm{NVC}$ cases and $8 \mathrm{VC}$ cases $(P=.0014) ; 5 \mathrm{NVC}$ cases and $4 \mathrm{VC}$ cases who required ECMO died within 30 days. There were 4 interstage deaths (after hospital discharge, 1 at 585 days without having undergone a BDG or Fontan procedure) in the VC group, 1 interstage death and 1 transplant in the NVC group, and 1 early post-BDG death in each group. Survival over time was significantly worse in NVC cases by Gray's test of cumulative incidence $(P=.040)$ (Figure 2, A), but this difference was no longer significant after stratification on surgical era (first half or second half) $(P=.23)$.

\section{Echocardiography}

Echocardiographic measures of RV size and function could be evaluated completely and reliably in $78 \mathrm{VC}$ cases $(78 \%)$ and in $20 \mathrm{NVC}$ cases $(66 \%)$ before both stage 1 and BDG procedures (Table 2). In $6 \mathrm{VC}$ cases and $2 \mathrm{NVC}$ cases, a BDG was not performed, but echocardiographic data were available at an age greater than 73 days (ie, age of the youngest patient who underwent successful BDG in this study) and were included in the echocardiographic analysis. The median ages were similar in the 2 groups at both echocardiographic time points. There was no difference between groups at either time point in quantitative measures of RV function or TV annulus diameter $z$ score. In both groups, the RV FAC and TV annulus diameter and $z$ score increased, whereas the TAPSE $z$ score decreased (all $P<.001$ ), but there were no differences in prestage 1 to pre-BDG change between groups in any of these variables. Although there was an increase in the prevalence of moderate or greater TR in both groups from prestage 1 to pre-BDG, there was no difference between conduit types.

Adequate color Doppler imaging at the level of the valve within the conduit was available in 64 patients after the stage 1 procedure (median 11 days post-Norwood; range, $1-55)$ and in 64 patients pre-BDG. Paired comparisons of 

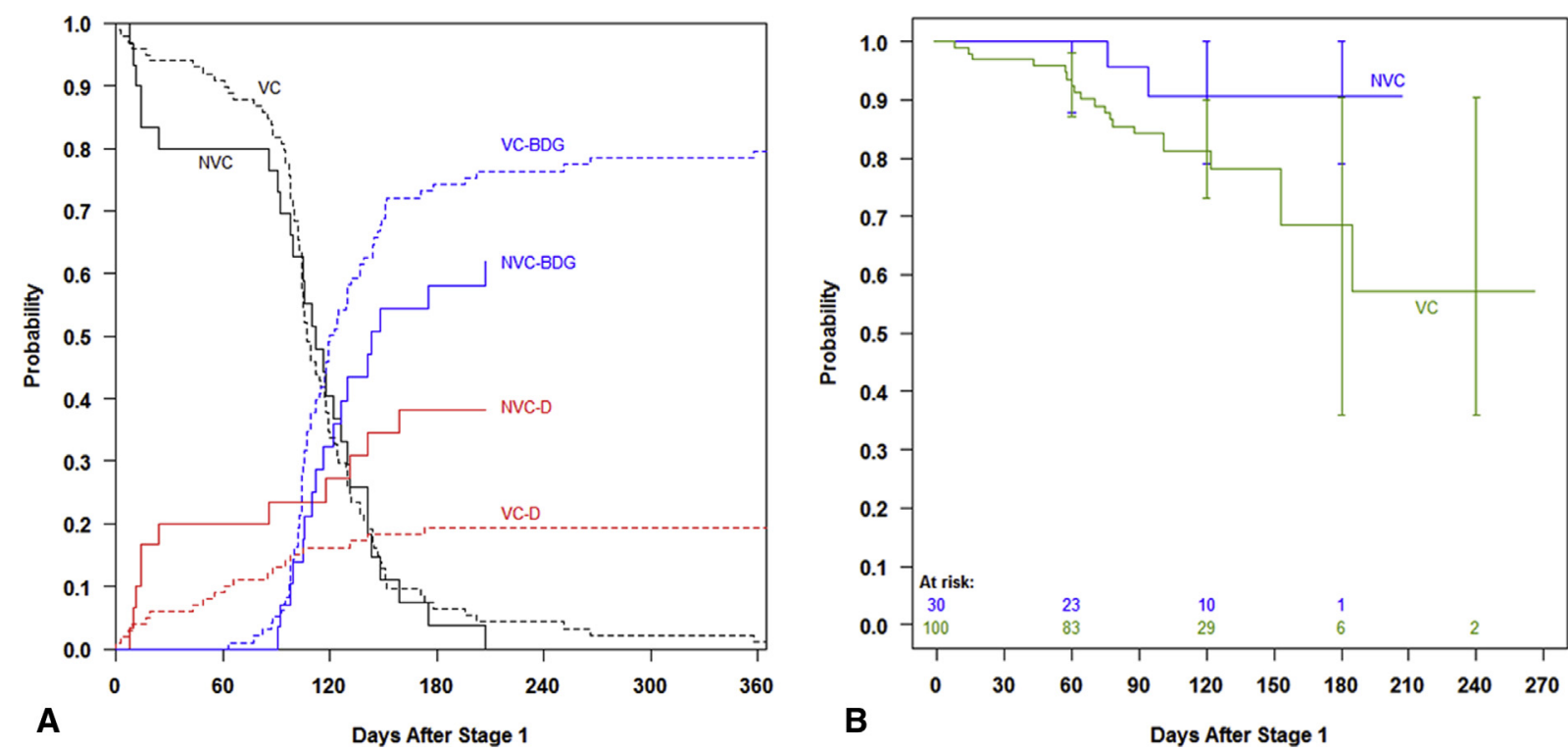

FIGURE 2. A, These competing outcomes curves demonstrate the probability of 3 mutually exclusive outcomes over time in VC (dashed lines) and NVC (solid lines) cohorts out to 1 year: death (red lines), completion of a BDG procedure with early survival (blue lines), and survival without a BDG (black lines). There was a significant difference in the probability of death over time $(P=.04)$, but this was no longer significant after stratification for surgical era. There was no difference in the probability of BDG completion with early survival $(P=.15)$. B, These Kaplan-Meier curves depict freedom from reintervention for conduit obstruction in the VC and NVC groups. Despite the divergence of curves over time, there was no significant difference $(P=.16)$. The number of patients at risk is summarized along the $\mathrm{x}$-axis and $95 \%$ confidence intervals are depicted with bars at $60,120,180$, and 240 days. $V C$, Valved conduit; $B D G$, bidirectional Glenn; $N V C$, nonvalved conduit.

both time points were available for 51 patients. Among 23 patients who had no identifiable conduit regurgitation after stage 1,9 subsequently developed regurgitation. Among the remaining 28 patients who had conduit regurgitation at baseline, the vena contracta width of the homograft valve regurgitation jet decreased in 5 , increased in 10 , remained unchanged in 3, and resolved completely in 10. Altogether, 24 patients had no identifiable conduit regurgitation preBDG (Figure E1). Among the 18 patients who had a measurable vena contracta at both time points, the width was $2.5 \pm 1.1 \mathrm{~mm}$ early after stage 1 and $3.0 \pm 1.1 \mathrm{~mm}$ before $\mathrm{BDG}(P=.13)$; the width-to-valve diameter ratio increased slightly in the interstage period but did not reach statistical significance (poststage 1: $0.37 \pm 0.16$, pre-BDG: $0.45 \pm 0.16, P=.12)$.

\section{Invasive Hemodynamics and Interventions}

Pre-BDG catheterization was performed at a similar age in both groups (median 99 days VC and 102 days NVC, $P=.39$ ) and demonstrated no difference in systemic oxygen saturation $(72 \% \pm 8 \%$ VC vs $73 \% \pm 7 \%$ NVC, $P=.52$ ) or the pulmonary-to-systemic blood flow ratio (Qp:Qs, $0.9 \pm 0.4 \mathrm{VC}$ vs $0.9 \pm 0.2 \mathrm{NVC}, P=.50$ ). Percutaneous or surgical interventions to augment or reduce pulmonary blood flow were performed in $23 \mathrm{VC}$ cases $(29 \%)$ and 4 NVC cases $(15 \%)$, as detailed in Table 3 (Video 1).
There was no significant difference in freedom from intervention between $\mathrm{VC}$ and NVC groups $(P=.31)$. Interventions for conduit obstruction were performed in $17 \mathrm{VC}$ cases and $2 \mathrm{NVC}$ cases, with no difference between groups $(P=.16)$ (Figures 2-4). This did not change with adjustment for conduit size, surgeon, patient age/weight, or era. In the VC group, smaller valve size was associated with shorter freedom from intervention for conduit obstruction (HR, 0.36 per $\mathrm{mm}$ [95\% confidence interval, 0.16-0.79], $P=.010$ ).

\section{DISCUSSION}

In patients undergoing stage 1 palliation for HLHS, the RV-PA conduit was originally adopted to reduce or eliminate problems encountered with an mBTS in achieving a stable balance between systemic and pulmonary blood flow, including (1) runoff during diastole that compromises coronary, cerebral, renal, and intestinal perfusion; and (2) a relatively high Qp:Qs contributing to a systemic ventricular volume load and the deleterious effects thereof, especially with larger shunts. Both higher diastolic pressure and a lower Qp:Qs have been confirmed in patients who receive a nonvalved RV-PA conduit compared with those with an mBTS. ${ }^{5}$ Further, these hemodynamic benefits have been associated with improved perioperative, interstage, and 12-month survival. ${ }^{3,5}$ However, there is concern for the 
TABLE 2. Echocardiographic data before stage 1 and bidirectional Glenn

\begin{tabular}{|c|c|c|c|c|c|c|}
\hline & \multicolumn{3}{|c|}{ Prestage 1} & \multicolumn{3}{|c|}{ Pre-BDG } \\
\hline & $\overline{V C}(n=78)$ & $\operatorname{NVC}(n=20)$ & $P$ value & $\overline{V C}(n=78)$ & NVC $(n=20)$ & $P$ value \\
\hline Age (d) & $1(0-24)$ & $1(0-10)$ & .60 & $107(34-275)$ & $115(89-210)$ & .35 \\
\hline 2-dimensional RV FAC (\%) & $36.9 \pm 9.3$ & $36.2 \pm 7.8$ & .72 & $38.7 \pm 8.3$ & $39.1 \pm 11.7$ & .89 \\
\hline TV annulus diameter $(\mathrm{cm})$ & $1.2 \pm 0.2$ & $1.2 \pm 0.3$ & .81 & $1.6 \pm 0.2$ & $1.6 \pm 0.2$ & .79 \\
\hline TV annulus z score & $0.8 \pm 1.0$ & $0.7 \pm 1.5$ & .90 & $2.2 \pm 1.4$ & $1.8 \pm 1.2$ & .24 \\
\hline 2-dimensional TAPSE $\mathrm{z}$ score & $-2.8 \pm 1.2$ & $-2.5 \pm 1.6$ & .43 & $-4.8 \pm 1.1$ & $-4.7 \pm 1.3$ & .89 \\
\hline Moderate or greater TR & $2(3 \%)$ & $0(0 \%)$ & 1.00 & $10(13 \%)$ & $3(15 \%)$ & .73 \\
\hline
\end{tabular}

Data presented as median (minimum-maximum), mean \pm standard deviation, or number (\%). Unpaired $t$ test and Fisher exact test were used for continuous and categoric data, respectively. By paired $t$ test overall, there was no significant change in $\operatorname{FAC}(P=.72)$ but significant increases (TV annulus diameter and $z$ score) or decreases (TAPSE $z$ score) from prestage 1 to pre-BDG (all $P<.001$ ). There were no differences between groups in the prestage 1 to pre-BDG change in any of the values. $B D G$, Bidirectional Glenn; $V C$, valved conduit; $N V C$, nonvalved conduit; $R V$, right ventricle; $F A C$, fractional area change; $T V$, tricuspid valve; TAPSE, tricuspid annular place systolic excursion; $T R$, tricuspid regurgitation.

negative effects of a ventriculotomy and free conduit regurgitation, as deterioration in $\mathrm{RV}$ ejection fraction has been observed in those with stage 2 and 3 in RV-PA conduit but not in those with an mBTS. ${ }^{14,15}$ Although the ventriculotomy cannot be eliminated, a reduction in diastolic conduit regurgitation could improve long-term $\mathrm{RV}$ function and outcomes more broadly in patients who undergo palliation with an RV-PA conduit.

Although we were not the first to use a composite valved RV-PA conduit, this is the largest and most comprehensive

TABLE 3. Interventions during the interstage period

\begin{tabular}{|c|c|c|}
\hline & $\begin{array}{c}\mathrm{VC} \\
\mathbf{n}=\mathbf{2 3}\end{array}$ & $\begin{array}{l}\text { NVC } \\
\mathrm{n}=\mathbf{4} \\
\end{array}$ \\
\hline \multicolumn{3}{|l|}{ Method of intervention } \\
\hline Percutaneous intervention & $19 *$ & 2 \\
\hline Surgical intervention & $6^{*}$ & 2 \\
\hline \multicolumn{3}{|l|}{ Timing of first intervention } \\
\hline Early (within $30 \mathrm{~d}$ of stage 1 ) & 6 & 2 \\
\hline Late (30 d or more after stage 1$)$ & 17 & 2 \\
\hline \multicolumn{3}{|l|}{ Indication and type of intervention } \\
\hline Intervention to increase pulmonary blood flow & 22 & 3 \\
\hline Conduit stent & 15 & 2 \\
\hline Proximal conduit only & $2 *$ & 1 \\
\hline Distal conduit only & 7 & 1 \\
\hline Both proximal and distal conduit & 6 & 0 \\
\hline Conduit balloon angioplasty without stent & 1 & 0 \\
\hline Branch PA balloon angioplasty & 3 & 0 \\
\hline RV myectomy at origin of conduit & 1 & 0 \\
\hline Added mBTS & 2 & 0 \\
\hline Conduit replaced with larger NVC & 1 & 0 \\
\hline Conduit replaced with central shunt & 0 & 1 \\
\hline Intervention to reduce pulmonary blood flow & 3 & 1 \\
\hline Surgical conduit clip & $2 *$ & 1 \\
\hline Covered stent with waist & 1 & 0 \\
\hline
\end{tabular}

$V C$, Valved conduit; $N V C$, nonvalved conduit; $P A$, pulmonary artery; $R V$, right ventricle; $m B T S$, Modified Blalock-Taussig shunt. *These numbers included 2 patients who underwent early surgical clipping of the conduit followed later conduit stenting. study to evaluate the hemodynamic consequences of a VC. Shortly after describing the first known palliative surgery for HLHS using a systemic-to-PA shunt, ${ }^{16}$ Norwood and colleagues $^{17}$ and Sano and colleagues ${ }^{18}$ described the RV-PA conduit as an alternative to establish pulmonary blood flow and reported their experience using both VC and NVC. The conduits used in that formative experience were large $(12 \mathrm{~mm})$, and excess pulmonary blood flow contributed to mortality. Drawing from Norwood's experience with VCs as well as that of Kishimoto and colleagues, ${ }^{19}$ Sano and colleagues ${ }^{18}$ first published their experience in 19 patients using smaller diameter (5-6 $\mathrm{mm}$ ) nonvalved PTFE conduits to limit pulmonary blood flow and improve perioperative survival. Since

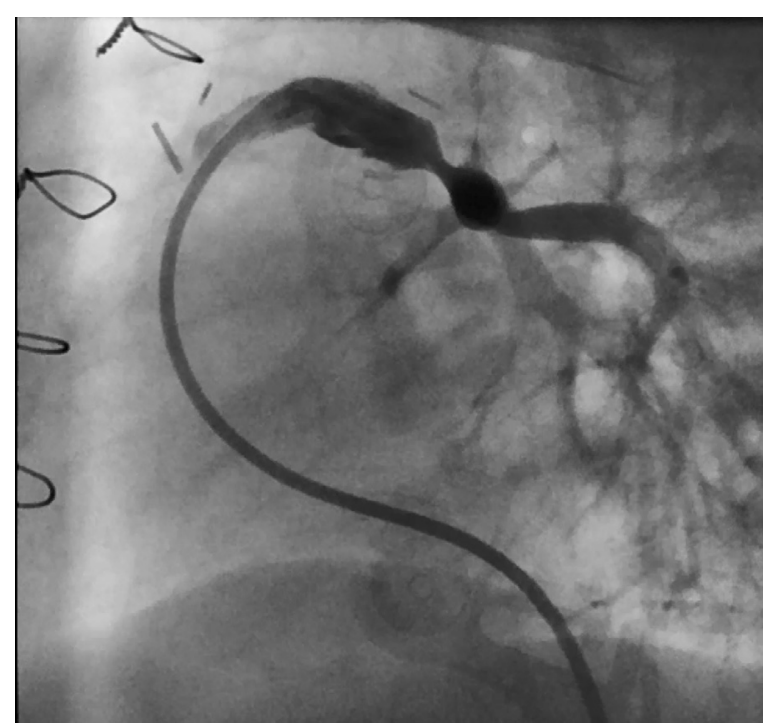

VIDEO 1. This angiogram in the lateral projection shows the RV-PA conduit in a patient with palliated HLHS. The tip of the catheter is just beyond well-functioning valve leaflets, but there is a stenosis distal to the valve leaflets. Video available at: http://www.jtcvsonline.org/article/ S0022-5223(17)32427-3/fulltext. 

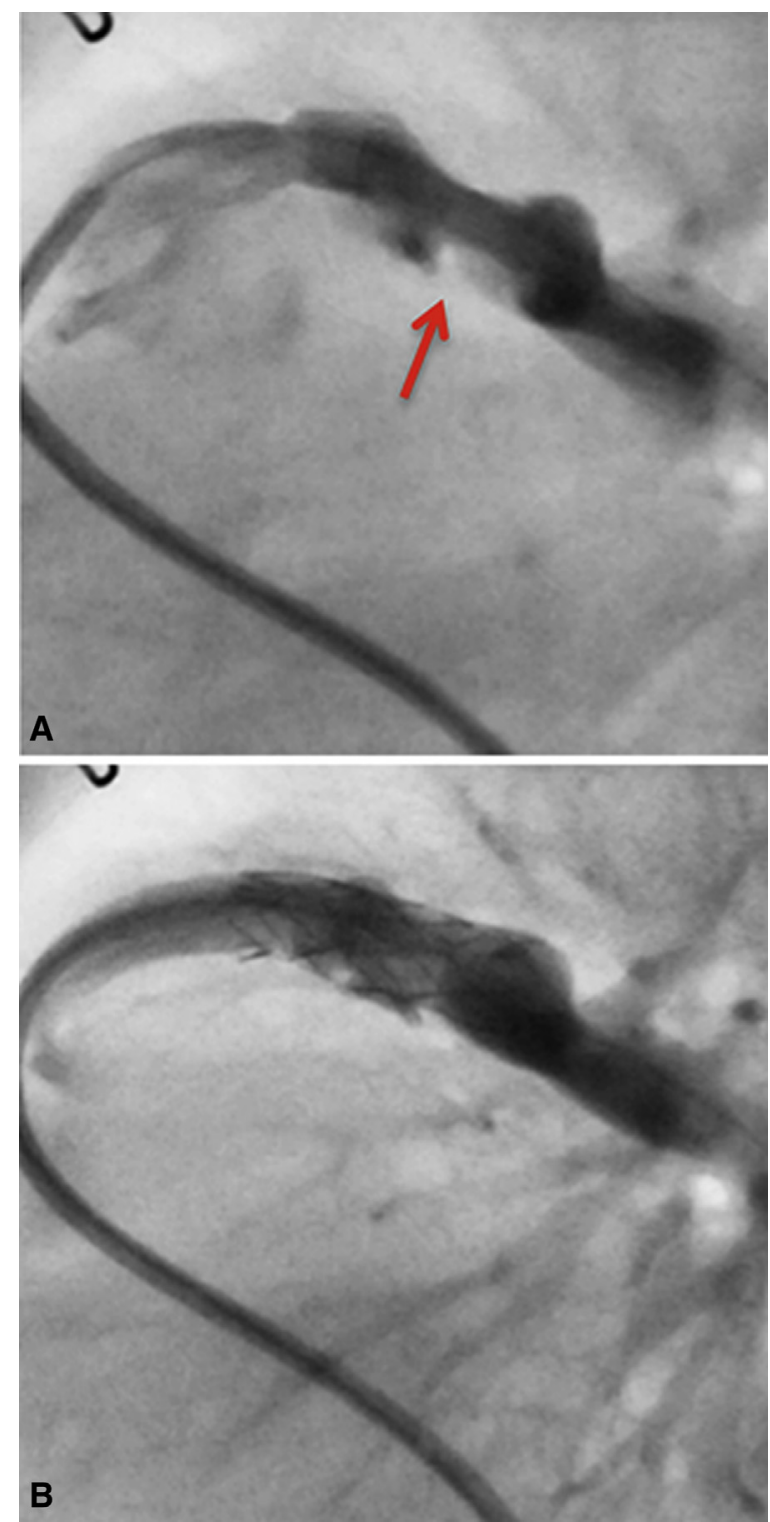

FIGURE 3. Prestent (A) and poststent (B) angiograms from a lateral projection in a patient who had distal obstruction of the RV-PA conduit that involved the homograft valve (arrow). This patient had a VC composed of a 7-mm aortic homograft valve on a 4-mm PTFE (Gore-Tex; WL Gore \& Associates Inc, Flagstaff, Ariz) tube.

then, various groups have incorporated valves into the RVPA conduit, including valved saphenous vein homografts, valved porcine xenografts, bovine pericardial conduits with porcine valves, and composite grafts using PTFE and Hemashield material. ${ }^{20-24}$ Most of these experiences were described as case reports or case series, the largest of which comprised 34 patients (21) and 8 patients (20), 5 and 4 of whom had a VC, respectively.

Currently, the significance of the diastolic conduit regurgitation on RV size and function in this population is not well understood. The most robust data to date were derived

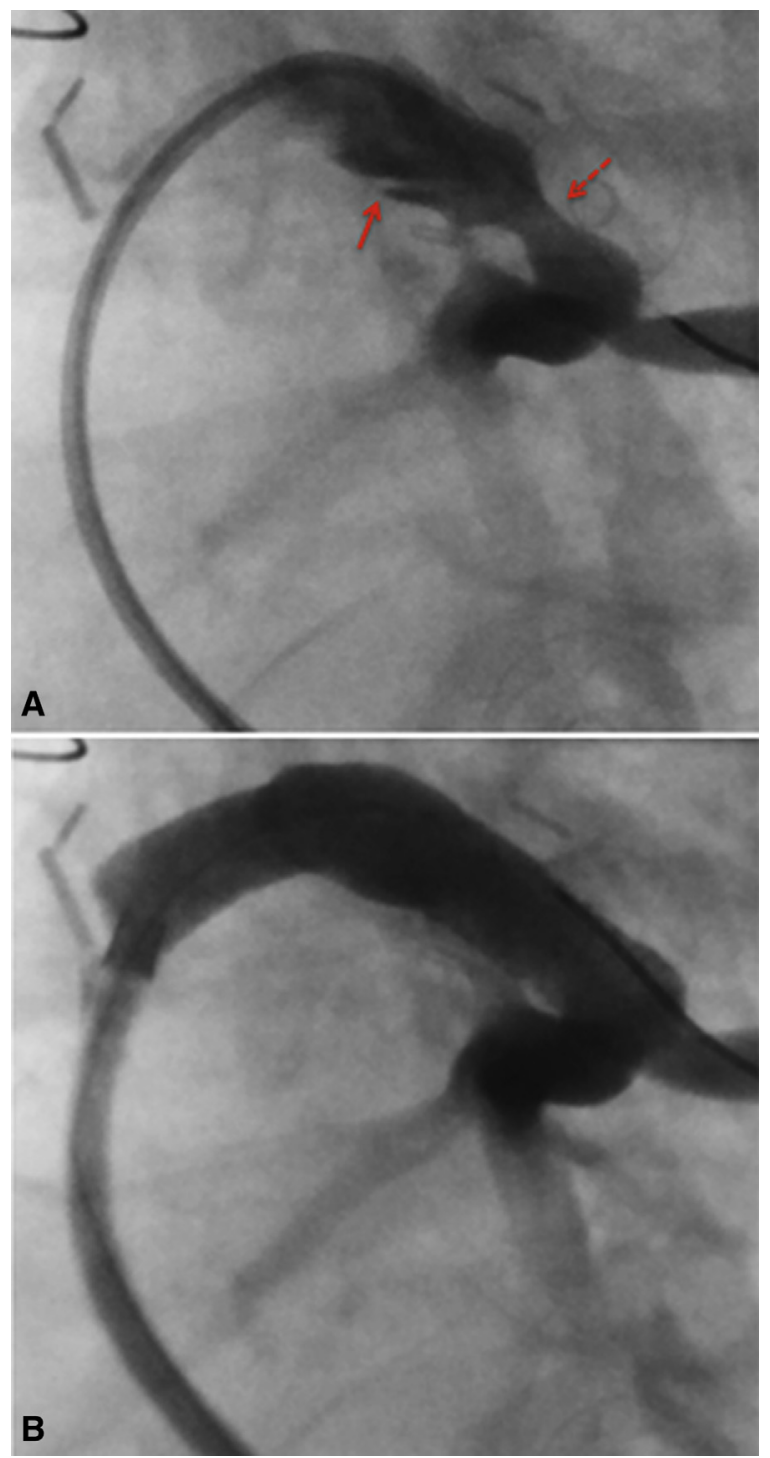

FIGURE 4. Prestent (A) and poststent (B) angiograms from a lateral projection in a patient who had obstruction of the RV-PA conduit (dashed arrow) that was distal to the homograft valve (solid arrow). This patient had a VC composed of a 6-mm aortic homograft valve on a 5-mm PTFE (Gore-Tex) tube.

from studies in which nonvalved RV-PA conduits were compared with mBTS. Mathematic modeling studies have suggested that diastolic regurgitation is minimal $(<7 \%)$ after palliation of HLHS with an RV-PA conduit but increases with increasing pulmonary vascular resistance (or potentially branch PA stenosis). ${ }^{25}$ Simulated pressurevolume analyses showed that, although RV mechanical efficiency with an RV-PA conduit is better than with a mBTS, there appears to be no additional value in adding a valve to the conduit. ${ }^{25,26}$ Our echocardiographic data are consistent with these predictions, showing no differences in RV dilation (represented by the TV annulus $z$ score) or RV function (by FAC) between groups at the prestage 1 or 
pre-BDG time points. The VC also did not have an appreciable effect on reducing the incidence of TR during the interstage period. However, the differences in early support with ECMO and survival over time, which favored the VC group on unadjusted analysis, may be an indication that the presence of a valve in the conduit promoted a more stable postoperative recovery. Along these lines, further analysis will be necessary to determine whether a VC imparts a protective effect immediately after the stage 1 procedure. For logistical reasons, we were unable to assess detailed data related to inotropic or other support in the intensive care unit, which might have provided some insight into this hypothesis.

Our data also highlight the challenges of using 2-dimensional echocardiography to quantify RV function in this setting. Although FAC increased from stage 1 to BDG, the TAPSE $z$ score paradoxically decreased. This discrepancy may suggest a complex adaptation and remodeling of the force generating contractile mechanisms of a volume- and pressure-loaded RV over time. Despite this limitation, our FAC data were similar to those from the Pediatric Heart Network Single Ventricle Reconstruction trial at both time points. ${ }^{27}$ Using both 2- and 3-dimensional echocardiography, those investigators showed no differences in RV function or the prevalence of significant TR between those undergoing mBTS and RV-PA conduit during the interstage period and up to age 14 months. ${ }^{27,28}$ Considering the lack of a measurable difference between patients with those vastly different shunt physiologies, it is not surprising that we did not observe a difference between the VC and NVC groups.

Although a higher Qp:Qs and systemic oxygen saturation might be expected in patients with a $\mathrm{VC}$, as was predicted in mathematic models, our data from the pre-BDG catheterization showed no difference. ${ }^{26}$ However, models may fail to account for other phenomena, such as patient growth and a biological system's natural tendency to restore equilibrium, ${ }^{25}$ and it is possible that VC cases transiently had higher pulmonary blood flow and systemic saturations than were captured in our study. Similar to our findings related to RV function, however, it is more likely that the inclusion of a valve in the RV-PA conduit does not significantly alter net pulmonary blood flow or that the benefit of a valve in the pulmonary circulation was neutralized by the development of conduit obstruction in some patients.

There was no statistical difference in freedom from intervention between VC and NVC groups, but there was a suggestive divergence of the Kaplan-Meier curves. Given our unequal sample size and nonrandomized retrospective design, however, it is difficult to discern whether inclusion of a homograft valve in a composite RV-PA conduit increases the risk of intervention. Multiple reports show that the standard nonvalved RV-PA conduit itself has a rate of intervention as high as $36 \%$, which increases to $41 \%$ when branch PA interventions are included. ${ }^{3}$ Freedom from reintervention (overall and for conduit obstruction) in both VC and NVC groups was within the range of what has been reported. Further, we previously reported a higher rate of interventions with aortic valve homografts compared with pulmonary valves, ${ }^{11}$ but there was no relationship between conduit type and frequency of interventions in the current analysis.

\section{Study Limitations}

In addition to the factors discussed, there were potentially important limitations to this study. Although an RV-PA conduit was used in essentially all patients undergoing stage 1 palliation of HLHS during the study period, the decision to implant a VC or NVC was at the discretion of the surgeon, and patient-related factors may have shaped this decision in a manner that resulted in uncontrolled confounding. Accordingly, the observed difference in survival according to conduit type may be related to other factors that were not accounted for, such as cardiopulmonary interactions in the early postoperative period, ${ }^{29}$ and as such cannot be attributed only to the use of a VC. Moreover, the focus of this analysis was on hemodynamic/functional parameters and conduit reinterventions that may have been related to the type of conduit used to connect the RV to the PAs.

Prior studies have shown that branch PA growth after stage 1 palliation differs according to the method of providing pulmonary blood flow, with better growth in patients who receive an RV-PA conduit. ${ }^{30-32}$ In theory, reduction of conduit regurgitation with a VC could augment this benefit, but we did not evaluate PA size in this study for logistical reason. However, given the lack of other hemodynamic and volumetric differences, we suspect that any such benefit would likely be modest at best.

\section{CONCLUSIONS}

This retrospective study showed that VC was associated with improved survival and stability after stage 1 palliation for HLHS on unadjusted analysis, but may also increase the risk of interventions to augment or reduce pulmonary blood flow during the interstage period. There was no detectable cardiac functional benefit from reducing RV-PA conduit regurgitation using a homograft valved composite conduit during stage 1 palliation, although benefits that were modest or limited to the interstage period cannot be ruled out.

\section{Conflict of Interest Statement}

Authors have nothing to disclose with regard to commercial support.

\section{References}

1. Khairy P, Poirier N, Mercier LA. Univentricular heart. Circulation. 2007;115: 800-12.

2. Wilder TJ, McCrindle BW, Phillips AB, Blackstone EH, Rajeswaran J, Williams WG, et al. Survival and right ventricular performance for matched 
children after stage-1 Norwood: Modified Blalock-Taussig shunt versus rightventricle-to-pulmonary-artery conduit. J Thorac Cardiovasc Surg. 2015;150: 1440-50.

3. Ohye RG, Sleeper LA, Mahony L, Newburger JW, Pearson GD, Lu M, et al. Comparison of shunt types in the Norwood procedure for single-ventricle lesions. N Engl J Med. 2010;362:1980-92.

4. Donnelly JP, Raffel DM, Shulkin BL, Corbett JR, Bove EL, Mosca RS, et al. Resting coronary flow and coronary flow reserve in human infants after repair or palliation of congenital heart defects as measured by positron emission tomography. J Thorac Cardiovasc Surg. 1998;115:103-10.

5. Mair R, Tulzer G, Sames E, Gitter R, Lechner E, Steiner J, et al. Right ventricular to pulmonary artery conduit instead of modified Blalock-Taussig shunt improves postoperative hemodynamics in newborns after the Norwood operation. J Thorac Cardiovasc Surg. 2003;126:1378-84.

6. Gray RG, Minich LL, Weng HY, Heywood MC, Burch PT, Cowley CG. Effect of endovascular stenting of right ventricle to pulmonary artery conduit stenosis in infants with hypoplastic left heart syndrome on stage II outcomes. Am J Cardiol. 2012;110:118-23.

7. Bentham JR, Baird CW, Porras DP, Rathod RH, Marshall AC. A reinforced right-ventricle-to-pulmonary-artery conduit for the stage-1 Norwood procedure improves pulmonary artery growth. J Thorac Cardiovasc Surg. 2015; 149:1502-8.

8. Munsterer A, Kasnar-Samprec J, Horer J, Cleuziou J, Eicken A, Malcic I, et al. Treatment of right ventricle to pulmonary artery conduit stenosis in infants with hypoplastic left heart syndrome. Eur J Cardiothorac Surg. 2013; 44:468-71.

9. Mery CM, LaPar DJ, Seckeler MD, Chamberlain RS, Gangemi JJ, Kron IL, et al. Pulmonary artery and conduit reintervention rates after Norwood using a right ventricle to pulmonary artery conduit. Ann Thorac Surg. 2011;92:1483-9.

10. Reinhardt Z, De Giovanni J, Stickley J, Bhole VK, Anderson B, Murtuza B, et al. Catheter interventions in the staged management of hypoplastic left heart syndrome. Cardiol Young. 2014;24:212-9.

11. Reinhartz O, Reddy VM, Petrossian E, MacDonald M, Lamberti JJ, Roth SJ, et al. Homograft valved right ventricle to pulmonary artery conduit as a modification of the Norwood procedure. Circulation. 2006;114(1 Suppl):I594-9.

12. Silverman NH, McElhinney DB. Echocardiography of hypoplastic ventricles. Ann Thorac Surg. 1998;66:627-33.

13. Siehr SL, Maeda K, Connolly AA, Tacy TA, Reddy VM, Hanley FL, et al. Mitral stenosis and aortic atresia- a risk factor for mortality after the modified Norwood operation in hypoplastic left heart syndrome. Ann Thorac Surg. 2016; 101:162-7.

14. Newburger JW, Sleeper LA, Frommelt PC, Pearson GD, Mahle WT, Chen S, et al. Transplantation-free survival and interventions at 3 years in the single ventricle reconstruction trial. Circulation. 2014;129:2013-20.

15. Frommelt PC, Gerstenberger E, Cnota JF, Cohen MS, Gorentz J, Hill KD, et al. Impact of initial shunt type on cardiac size and function in children with single right ventricle anomalies before the Fontan procedure: The Single Ventricle Reconstruction Extension Trial. J Am Coll Cardiol. 2014;64:2026-35.

16. Norwood WI, Kirklin JK, Sanders SP. Hypoplastic left heart syndrome: experience with palliative surgery. Am J Cardiol. 1980;45:87-91.

17. Norwood WI, Lang P, Casteneda AR, Campbell DN. Experience with operations for hypoplastic left heart syndrome. J Thorac Cardiovasc Surg. 1981; 82:511-9.

18. Sano S, Ishino K, Kawada M, Arai S, Kasahara S, Asai T, et al. Right ventriclepulmonary artery shunt in first-stage palliation of hypoplastic left heart syndrome. J Thorac Cardiovasc Surg. 2003;126:504-9.
19. Kishimoto H, Kawahira Y, Kawata H, Miura T, Iwai S, Mori T. The modified Norwood palliation on a beating heart. J Thorac Cardiovasc Surg. 1999;118: 1130-2.

20. Takeuchi K, Murakami A, Takaoka T, Takamoto S. Evaluation of valved saphenous vein homograft as right ventricle-pulmonary artery conduit in modified stage I Norwood operation. Interact Cardiovasc Thorac Surg. 2006;5:345-8.

21. Dähnert I, Riede F, Razek V, Weidenbach M, Rastan A, Walther T, et al. Catheter interventional treatment of Sano shunt obstruction in patients following modified Norwood palliation for hypoplastic left heart syndrome. Clin Res Cardiol. 2007; 96:719-22.

22. Murakami A, Takamoto S, Takaoka T, Kobayashi J, Maeda K, Takayama H, et al Saphenous vein homograft containing a valve as a right ventricle-pulmonary artery conduit in the modified Norwood operation. J Thorac Cardiovasc Surg. 2002;124:1041-2.

23. Yamashiro M, Morita K, Uno Y, Shinohara G, Hashimoto K. Modified Norwood procedure with a handmade down-sizing valved right ventricle-to-pulmonary artery conduit. Gen Thorac Cardiovasc Surg. 2011;59:30-3.

24. Ginestar AC, Martinez FS, Argudo JA, Calvar JM. Norwood-Sano operation using a stentless pulmonary valved conduit. World J Pediatr Congenit Heart Surg. 2011;2:133-5.

25. Bove EL, Migliavacca F, de Leval MR, Balossino R, Pennati G, Lloyd TR, et al. Use of mathematic modeling to compare and predict hemodynamic ef fects of the modified Blalock-Taussig and right ventricle-pulmonary artery shunts for hypoplastic left heart syndrome. J Thorac Cardiovasc Surg. 2008; 136:312-20.

26. Shimizu S, Une D, Shishido T, Kamiya A, Kawada T, Sano S, et al. Norwood procedure with non-valved right ventricle to pulmonary artery shunt improves ventricular energetics despite the presence of diastolic regurgitation: a theoretical analysis. J Physiol Sci. 2011;61:457-65.

27. Frommelt PC, Guey LT, Minich LL, Bhat M, Bradley TJ, Colan SD, et al. Does initial shunt type for the Norwood procedure affect echocardiographic measures of cardiac size and function during infancy?: The Single Ventricle Reconstruction Trial. Circulation. 2012;125:2630-8.

28. Marx GR, Shirali G, Levine JC, Guey LT, Cnota JF, Baffa JM, et al. Multicente study comparing shunt type in the Norwood procedure for single-ventricle lesions: three-dimensional echocardiographic analysis. Circ Cardiovasc Imaging. 2013;6:934-42.

29. Shakti D, McElhinney DB, Gauvreau K, Yarlagadda VV, Laussen PC, Betit P, et al. Pulmonary deadspace and postoperative outcomes in neonates undergoing stage 1 palliation operation for single ventricle heart disease. Pediatr Crit Care Med. 2014;15:728-34.

30. Pruetz JD, Badran S, Dorey F, Starnes VA, Lewis AB. Differential branch pulmonary artery growth after the Norwood procedure with right ventricle-pulmonary artery conduit versus modified Blalock-Taussig shunt in hypoplastic left heart syndrome. J Thorac Cardiovasc Surg. 2009;137:1342-8.

31. Rumball EM, McGuirk SP, Stumper O, Laker SJ, de Giovanni JV Wright JG, et al. The RV-PA conduit stimulates better growth of the pulmonary arteries in hypoplastic left heart syndrome. Eur J Cardiothorac Surg. 2005;27:801-6.

32. Caspi J, Pettitt TW, Mulder T, Stopa A. Development of the pulmonary arteries after the Norwood procedure: comparison between Blalock-Taussig shunt and right ventricular-pulmonary artery conduit. Ann Thorac Surg. 2008;86:1299-304.

Key Words: bidirectional Glenn, hypoplastic left heart syndrome, right ventricular function, tricuspid regurgitation 


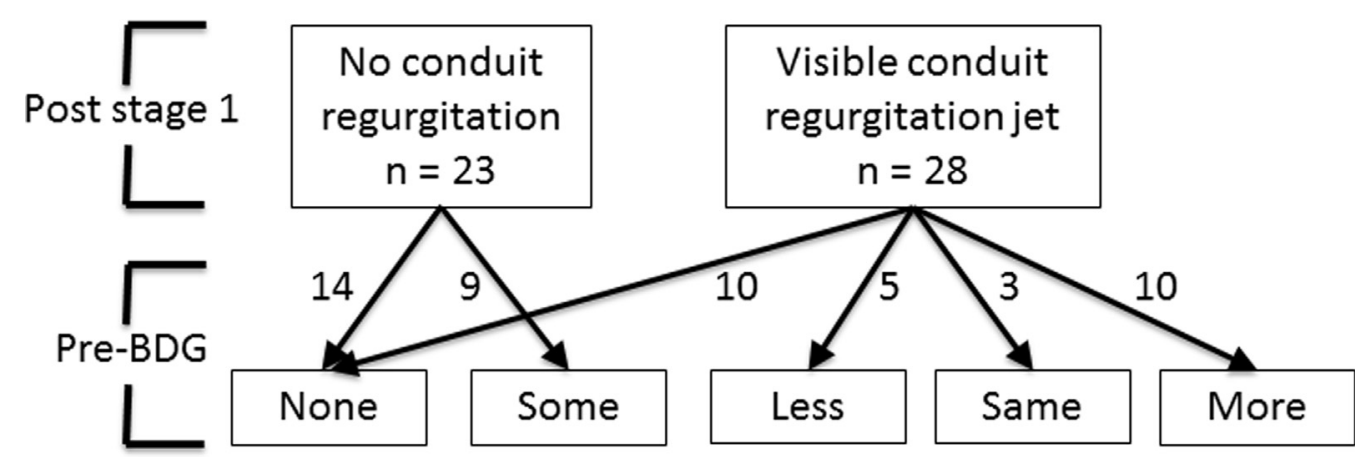

FIGURE E1. This flow diagram depicts the distribution of conduit regurgitation early after stage 1 and on the pre-BDG echocardiogram in the patients in the $\mathrm{VC}$ group for whom it was characterized in the early poststage 1 period. $B D G$, Bidirectional Glenn. 